\title{
Shale Gas Characterization of Sembar Formation, Khipro Area, Pakistan
}

\author{
Muhammad Sohail Khan ${ }^{*}$, Zainab Bibi2 ${ }^{*}$ \\ ${ }^{1}$ School of Earth and Space Sciences, University of Science and Technology of China, Hefei, China \\ ${ }^{2}$ Department of Earth Sciences, Quaid-i-Azam University, Islamabad, Pakistan \\ Email: sohailabbottabad@yahoo.com, znbkhan2046@gmail.com
}

Received 27 June 2016; accepted 14 August 2016; published 17 August 2016

Copyright (C) 2016 by authors and Scientific Research Publishing Inc.

This work is licensed under the Creative Commons Attribution International License (CC BY).

http://creativecommons.org/licenses/by/4.0/

(c) () Op Open Access

\section{Abstract}

This study pertains to the evaluation of shale gas and rock physics properties of this area with respect to its total organic content of Sember Formation, Khiproarea, Pakistan. We use well logs data for this study. The Khipro area is prominent in the Lower Indus Basin for its hydrocarbon (oil and gas) structural traps. In shale gas evaluation, TOC of Sember Formation is estimated. The analysis has been done with the help of the wire line data of the well Bilal North-01. The presence of shale gas in the study area is analyzed with the help of different techniques. Rock physics and petrophysical analysis have been done in order to get the properties of the area related to the shale gas evaluation.

\section{Keywords}

Shale Gas Reservoir Characterization, Well Log Response in Shale Gas, Methods to Compute TOC, Rock Physics Model for Shale Gas

\section{Introduction}

The study area, Khipro Block is tectonically situated in Southern Indus Basin and geographically in the Sanghar district Sindh province of Pakistan. Southern Indus Basin is very important for hydrocarbon exploration because it is the main producing oil and gas basin of Pakistan. Khipro is located in the Thar platform area of Southern Indus Basin. The Khipro area is characterized by a series of horst and graben structures present almost below the base Paleocene unconformity within the Cretaceous. The geographical co-ordinates of the area are listed:

- Latitude $25^{\circ} 20^{\prime} \mathrm{N}$ to $26^{\circ} 30^{\prime} \mathrm{N}$.

- Longitude $68^{\circ} 20^{\prime} \mathrm{E}$ to $69^{\circ} 14^{\prime} \mathrm{E}$.

*Both authors have equal contribution for this paper. 
Rifting and breaks up Gondwana land in Jurassic period is responsible for the formation of Khipro block baisan. The East Gondwana plate (India, Antarctica and Australia) separated from the West Gondwana plate (Africa and South America) in the Cretaceous period. In Aptian time (120 Ma), the Indian plate separated from east Gondwana [1] defines in article "A Speculative Tectonichistory of Pakistan and Surroundings" that at the end of Cretaceous, Seychelles and Madagascar separated from India with associated faulting resulting in basaltic flows (Deccan Volcanism) in the southern part of Lower Indus basin. After Paleocene there was continuous oblique convergence of Asian plate and Indian plate throughout Tertiary time and the collision results in tilting of the entire region. Deposition during the rifting is shown by the presence of Jurassic rocks in the area. Due to rifting normal faulting and horst and graben structures are formed. The famous among these structures include "Sukkur Rift". However, this localized rifting phase was unable to continue after the Paleocene-Eocene time [1]. Below is the Geographic location map of study area [2] (Figure 1).

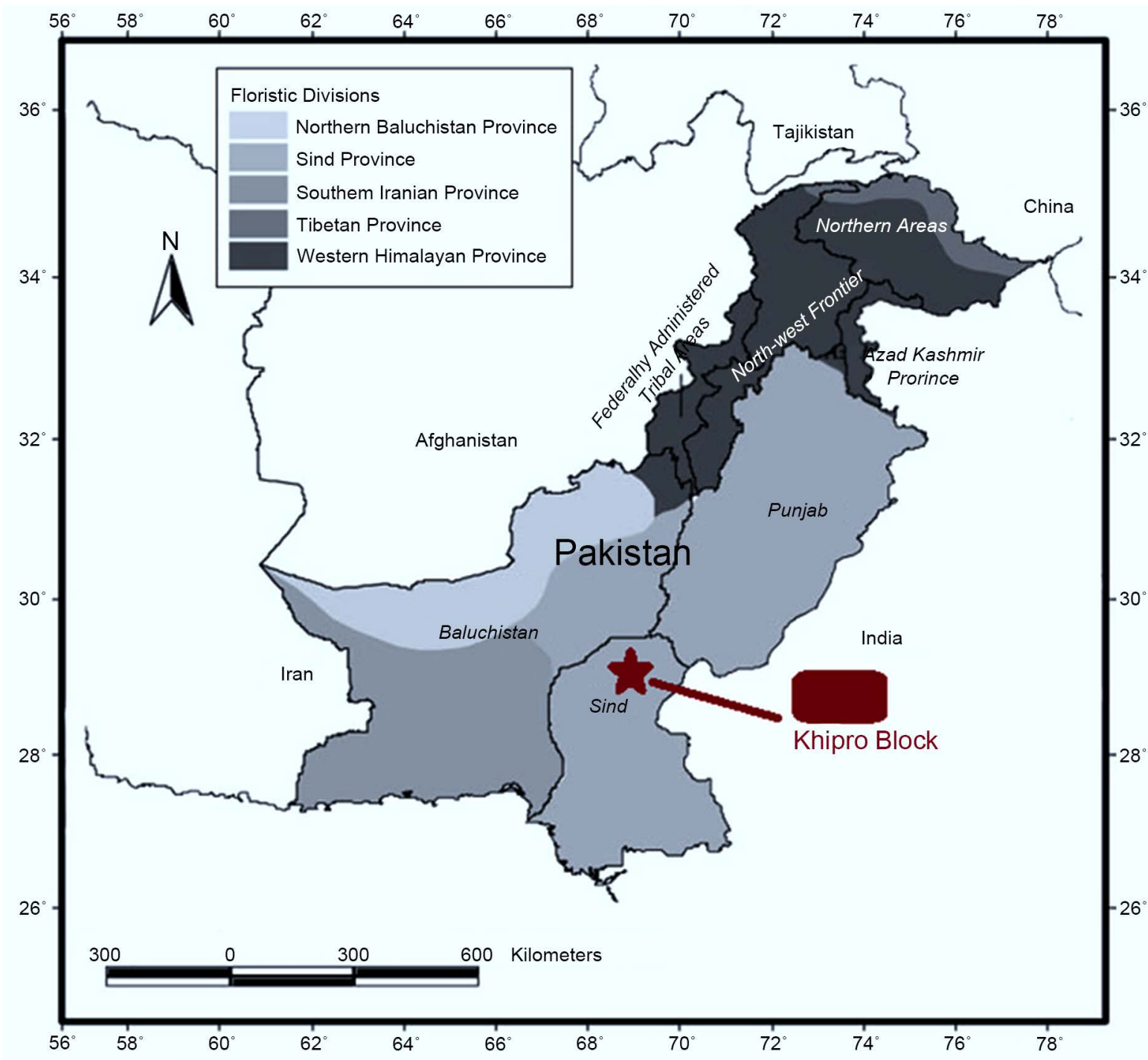

Figure 1. Geographic location of study area (Banks and Warburton, 1986).

\section{Objectives and Stratigraphy of the Area}

The studies carry out to identify the zone of organic rich shale from non-source shale and to estimate TOC of Sember Formation in area under study, using methodology based on sonic and density log with the combination of resistivity Passive method [3]. Bilal North 01 well with complete well logging data is utilized for this purpose. 
Then to observe the effect of TOC on rock physics parameters to determine the shale characterization of Sember Formation of Lower Indus Basin Pakistan. It is very critical to have knowledge about the stratigraphy of the area for the hydrocarbons prospecting, by this knowledge it is determined that what are the source, reservoirs and seals rocks of the area. The lithological setting and stratigraphic sequence of the study area which is our interest zone is as follows: Goru Formation, Upper Goru, Lower Goru, Sember Formation. Generalized stratigraphic column of the study area [4] (Figure 2).

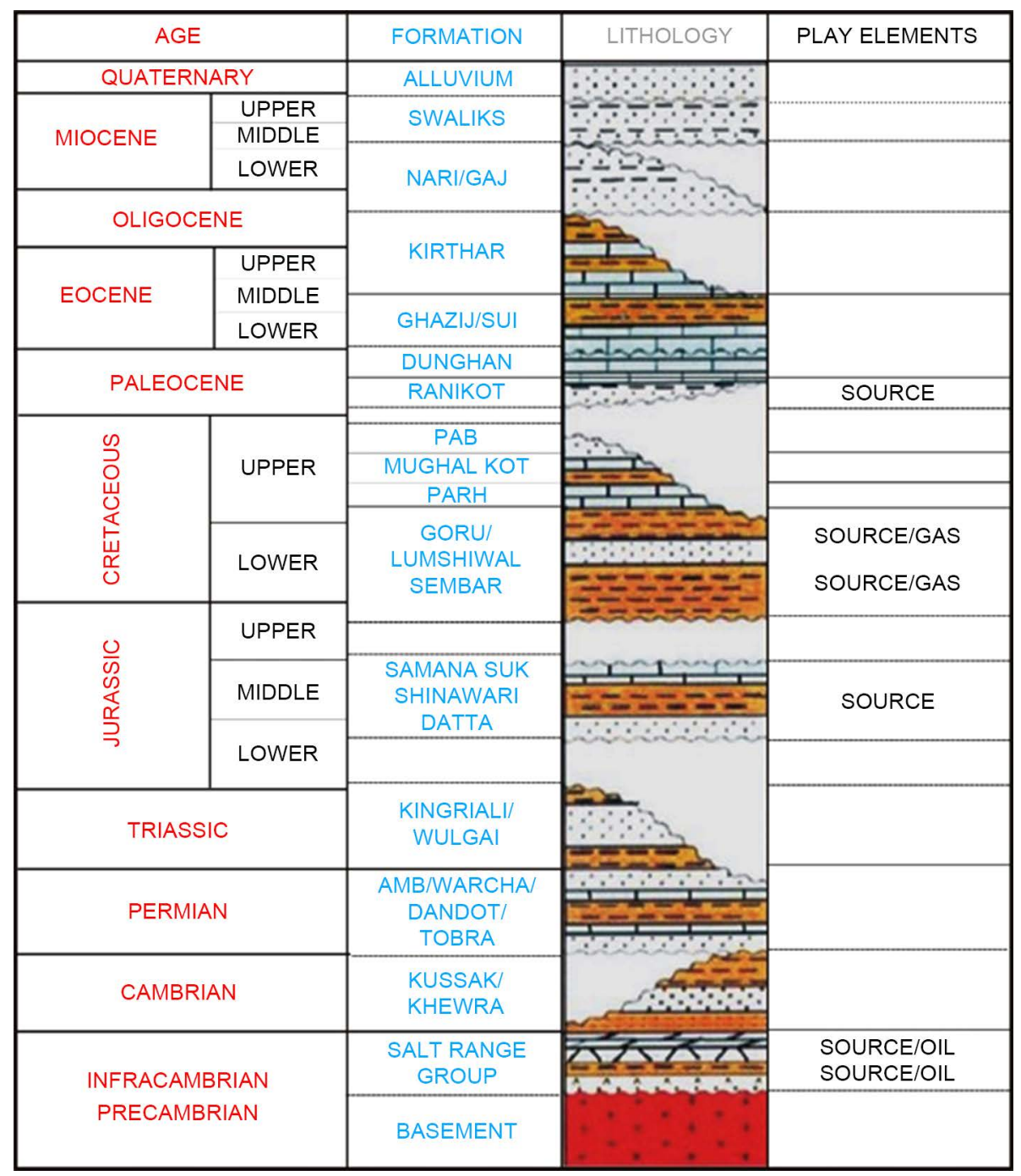

Figure 2. Generalized stratigraphic column of the study area (Quadri, 1986).

\section{Data and Methodology}

For this research was acquired as part of a project to reassess the oil and gas exploration potential through a regional potential field data survey of the area and a seismic data survey of Khipro area Pakistan. To achieve the desired objective we used following methodologies.

- Reservoir characterization.

- Shale gas reservoir characterization.

- Well log response in shale gas.

- Methods to compute TOC.

- Rock physics.

- Model for shale gas. 


\section{Shale Gas Reservoir Characterization}

In conventional petroleum system, carbonates and sandstones form the reservoir rocks and shales act as a source and seal rock. Since the last decades, shales have also been emerged as a good reservoir because of high porosity and very low permeability. Thus shales are considered as source rock as well as reservoir rock and seal too in terms of unconventional shale gas reservoirs. These shales have variability in term of mineralogical, elastic and physical properties from basin to basin and even within the basin [5]. The characterization of conventional reservoirs are well established from the seismic and wireline logging techniques, but in case of shale gas reservoirs, thickness, Saturation, porosity, fracture, brittleness, etc. are the characteristics in the development of shale gas play. The gas may be trapped as free gas in natural fractures and inter granular porosity, as gas absorbed into kerogen and clay or gas dissolved in kerogene and bitumen where gas may be biogenic and thermo genic and may be mixture of both. The source rock is mainly depending on the estimation of total organic content and level of maturity of source rock and done through the geochemical sedimentological methods. The organic content in the source rock has specific velocity, density and resistivity characteristics which affect log and seismic responses [6]. Thus source-shales and hence shale-gas reservoirs can be characterized through logs and seismic. Kerogen is the insoluble fraction of organic matter which usually constitutes $80 \%$ to $90 \%$ organic content. Vitrinite reflectance is a key parameter that indicates the maturity of organic material to calibrate the thermal and burial history models (Figure 3) [3].

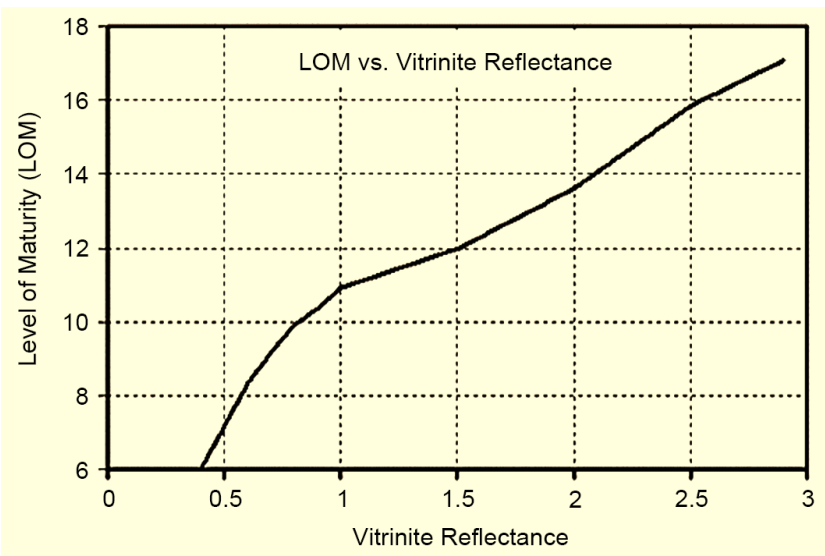

Figure 3. LOM vs vitrinite reflectance (Passey et al., 2010).

Factors affecting accurate Ro measurement:

- Rough textured vitrinite.

- Weathered.

- Partially dissolved (pitted).

- Fractured.

- Oxidized vitrinite.

- Inclusions.

- Pyrite.

- Bitumen.

- Other macerals.

- Too few readings $(<20)$.

Gas producing shales are typically the source rocks that also function as reservoir rock. Apart from low permeability of shales, the key properties for a gas shale reservoirs far a successful shale gas play, the following characteristics need to be considered:

1) Total organic carbon (TOC).

2) Reservoir thickness.

3) Thermal maturity ( $R \%)$.

4) Reservoir characteristics (brittleness etc.).

5) Gas-in-place. 
Shale which have sufficient TOC may generate hydrocarbon at favorable temperature and pressure conditions. Combination of these factors lead to favorable productivity and the depth of the shale gas formation should also be considered as it will have a bearing on the economics of the gas recovery.

\section{Total Organic Carbon and Thermal Maturity}

TOC is basically the amount of carbon bound in organic compounds of the rock. TOC has primarily been used to evaluate the quality of source rock although it is now also used in evaluation of unconventional reservoirs. TOC and kerogene are closely associated with shales and silt rich claystone however they can also be present in many carbonates. TOC is expressed as a percentage by weight present in rock [7]. Economic shale gas development candidates require sample organic matter to generate sufficient volumes of hydrocarbons i.e., relatively high TOC. TOC values ranges from $2 \%$ to $10 \%$ have good exploration targets [8]. Classify the shale rocks to be act as potential source of shale gas based on TOC contents. This classification is given in Table 1.

\begin{tabular}{|cc|}
\hline Table 1. Classification of source potential on TOC content. \\
\hline Total organic carbon (\%) & Source potential \\
\hline$<0.5$ & Very poor \\
0.5 to 1 & Poor \\
1 to 2 & Fair \\
2 to 4 & Good \\
4 to 10 & Very good \\
$>10$ & Unknown \\
\hline
\end{tabular}

Thermal maturity is one of the most important parameters used in the evaluation of gas-shale and shale-oil plays. Vitrinite reflectance $\left(R_{o}\right)$ is a commonly used thermal maturity indicator. Thermal maturity of organic matter represents the critical element of thermogenic Shale Gas. Vitrinite reflectance is the key factor for estimating the level of thermal maturity of organic matter (LOM). The measurement of $R_{o}$ was originally developed to rank the coal maturity [9].

Table 2. Interpreted maturity stages (Alexander et al., 2011).

\begin{tabular}{cc}
\hline Thermal maturation & $R_{o} \%$ \\
\hline Immature & $<0.6$ \\
Oil windows & $0.6-1.1$ \\
Wet gas windows & $1.1-1.4$ \\
Dry gas windows & $1.4-\sim 3.2$ \\
Gas destruction & $>\sim 3.2$ \\
\hline
\end{tabular}

Above $0.6 \% R_{o}$ value is the indicator of immature kerogen not having sufficient thermal conditions for conversion of organic material to hydrocarbon shown in Table 2 . The thermal maturity determines whether a source rock can produce oil, gas or condensate [10].

\section{Well Log Response in Shale Gas}

Organic-rich rocks are usually composed of three components i.e., rock matrix, solid organic matter and the fluid(s) filling the pore space, while non-source rocks are composed primarily of only two components i.e., the rock matrix and the fluid filling the pore spaces. As the source rock matures, a portion of the solid organic matter is transformed to liquid (or gaseous) hydrocarbons which move into the pore space, displacing the formation water. These physical transformations affect the porosity, density and resistivity of the rocks and hence reflected in their electric logs. To identify the organic rich rock, gamma ray log gives high values at the interval. This tool distinguishes the clay rich strata and sandy layers. The relationship between Natural gamma ray log and organic matter has been described by [11]. The quantitative interpretation of natural gamma ray log at organic rich interval suggests that such intervals do not have a high gamma ray value. So from analysis it is resulted that ura- 
nium con tent cause the high gamma ray value absorbed by the organic matter in marine sediments. Recently spectral gamma ray tool has been used to identify the organic matter because of empirical relationship between uranium and organic matter. Resistivity of rocks is depending on the fluid present in pore spaces of rock. In conventional reservoirs formation water is electrically conductive at least when he fluid is saline that allows the ionic conductivity. In these formations the resistivity value is very low due to the large volume of the formation water. When the formation water is displaced by the significant amount of hydrocarbon is non-conductors in the shale gas reservoirs, the response of resistivity log is dramatically increased in organic rich source rock that indicates the generation of hydrocarbon. The resistivity log depends on the free hydrocarbons present in the pores and not on a solid organic matter present in it. The response of resistivity log is also associated with the degree of maturity that implies the amount of hydrocarbon in pores. The presence of low density grain (kerogen) organic matter, the density log response at organic rich source interval gives the low value. The normal average value of density in mixture of clay minerals is about $2.7 \mathrm{~g} / \mathrm{cm}^{3}$. Thus the overall organic rich shale bulk density marked the effect on density log as low value. Combined with the resistivity log, density log give the extremely valuable results in organic rich source interval. Due to the presence of organic matter such as hydrocarbons in shale, the sonic log response give the low value of P-wave velocity due to the high transit time value similar to the density log response. Shear wave velocity response is also affected by the TOC. The use of sonic log can be enhanced to determine the TOC when combined with the resistivity log. Neutron log response gives the high value of porosity along the organic rich interval. But the log is not good indicator of organic matter as single tool because it is not affected by only the presence of hydrogen in organic matter, but also by the hydroxyl ion $\left(\mathrm{OH}^{-}\right)$ in clay minerals, hydrogen present in the formation water and even any form of hydrocarbons present in pores. For shale gas formations, the overlay of density/neutron is useful for identification of the higher gas volume but this technique is only applicable when the formation is not clay rich.

\section{Methods to Compute the TOC}

Shale gas reservoirs have the capability of self-generated and self-stored hydrocarbons. Due to the unique physical properties of organic matter shale gas reservoirs, the well logging response will be definitely different relative to the non-hydrocarbons shale. The well logging response in these reservoirs shows the high acoustic transit time, high resistivity, high Gamma-ray and low density. As a result, integrated with certain techniques, using the different well logging response between non-hydrocarbon source rocks and hydrocarbon source rocks to identify and calculate TOC is available [12]. The TOC is the fundamental indicator for the evaluation of shale gas reservoirs. Usually the TOC is the measured by the cores, cutting or sidewall cores in the laboratory with source rock evaluation instruments. Due to the limited number of core samples, the experimental results are not continuous and it is impossible to show the whole face of a source rock bed. So the continuous logging tool information contributes to show whole face of source rock bed shown in (Figure 4). From well logs, several methods have been published to calculate the TOC. Four common methods for TOC calculation such as 1 ) directly by regression of core TOC with core bulk density; 2) $\Delta \log R$ technique; 3) based on the petro-physics response model; 4) using an artificial neutral network). The bulk density regression method gives the satisfactory results when the formation is fairly homogeneous, but in the case of heterogeneity, this method will show result in poor co-relations. In petro-physical model, to determine the amount of TOC/kerogen, this model requires accurate porosity values. Unfortunately the porosity and kerogen content cannot separate from neutron and density log, and the Gamma-ray log readings are affected by the variable kerogen content of shale gas formation. To determine the effective porosity and shale content from shaleg as interval logs such as NMR and spectral-lite logs are required. The artificial neural network can use one or multi-log curves to estimate other log properties [13], but the technique needs extensive trial and error to select partial samples to overcome the over-learning problems. In a highly heterogeneous case, the method is difficult to predict the TOC because some meaningful core samples might not be available for the neural network training. The most common method which is widely used for TOC determination in shale gas plays is $\Delta \log R$ technique to calculate the $\Delta \log R$ based on the separation between the deep resistivity curve and the three porosity logs such as density, neutron and sonic logs can be used, which can be converted into TOC through the parameter of level of organic maturity (LOM). LOM is obtained from various methods of samples analysis (e.g., vitrinite reflectance, thermal alteration index and Tmax), or estimated using burial and thermal history of the basin. LOM determine the source rock quality either it can produce oil, gas or condensates. The technique of Rock-Eval pyrolysis as a standard method is used in the petroleum exploration [14]. This method computes the thermal maturation of the source rock. Thermal maturity parameters 


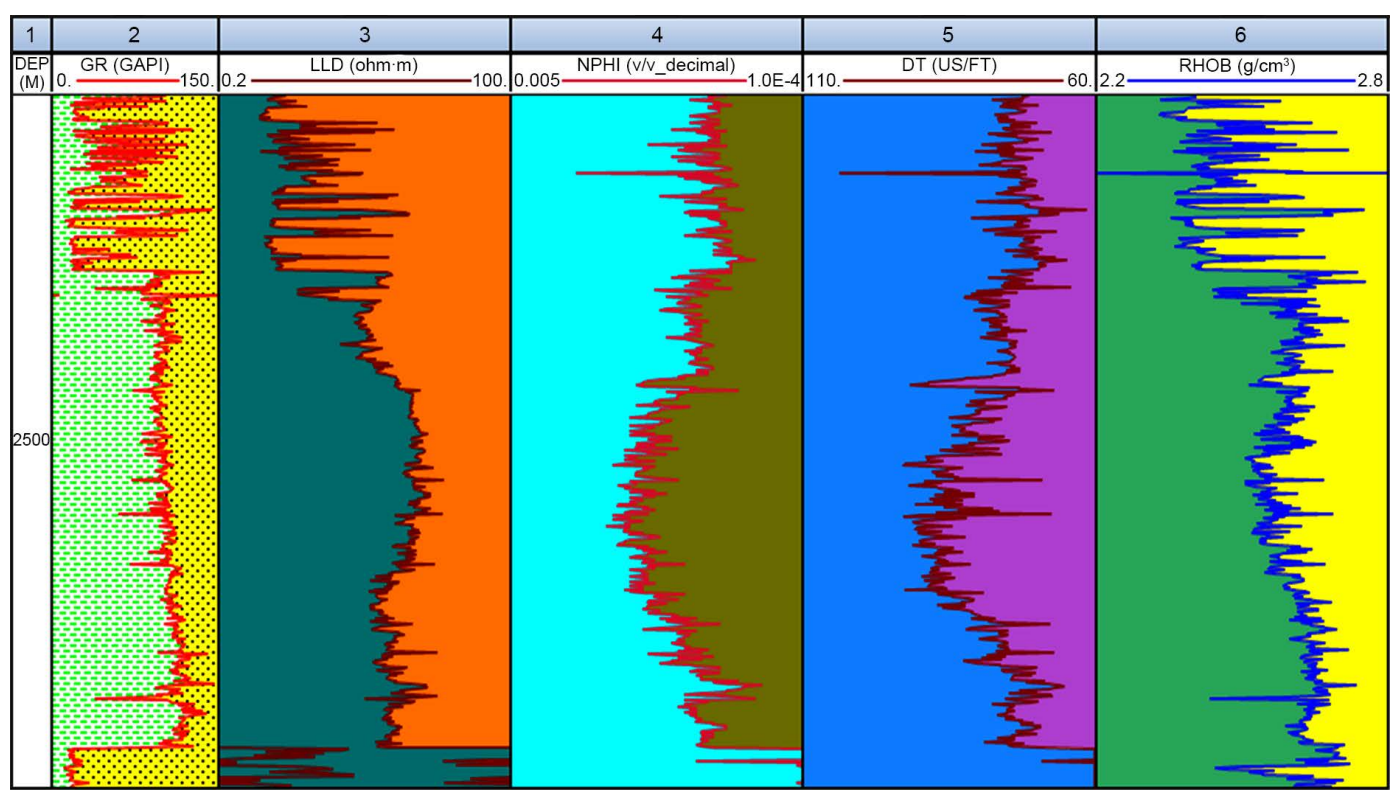

Figure 4. Logging results of Bilal North-01, track description is as follows: Track 1: Depth; Track 2: Gamma Ray; Track 3: Resistivity Log; Track 4: Neutron Log; Track 5: Sonic Log; Track 6: Density Log.

based on the maximum temperature (Tmax) to determine the dimensions of oil windows. A single scale which synthesizes several existing indices of organic maturity based on coal rank. The scale relates LOM to vitrinite reflectance among other indicators. LOM is unit less. We have analyzed our well: Bilal-01 lower Indus basin Pakistan. Due to lack of core data, conventional well data is used, including gamma-ray, resistivity, sonic and density for TOC calculation. We used Passey's method to identify source rock intervals. In this method, the two curves such as sonic and density log with respect to resistivity log curve are according. Where two curves are overlain on each other at significant depth range, a baseline condition exit in a fine grained indicate the nonsource rock. This baseline separates the non-organic rock interval from organic rich interval and this separation between them designated as $\Delta \log R$ that is linearly related to TOC. The expression for the calculation of $\Delta \log R$ from the sonic/resistivity curve overlay is

$$
\begin{gathered}
\Delta \log R=\log \left(R / R_{\text {baseline }}\right)+0.02 *\left(\Delta t-\Delta t_{\text {baseline }}\right) \\
\Delta \log R=\log \left(R / R_{\text {baseline }}\right)-2.5 *\left(\rho_{b}-\rho_{\text {baseline }}\right)
\end{gathered}
$$

where $\Delta \log R$ is the curve separation measured in logarithmic resistivity cycles, $r$ is the true resistivity log reading, $\Delta t$ is the sonic log reading, $\rho$ is the density log reading, $R_{\text {baseline, }} \Delta t_{\text {baseline }}$ and $\rho_{\text {baseline }}$ are the base-lined resistivity sonic and density readings in front of non-source shale, and 0.02 and 2.5 is a constant based on the shale between sonic, density and resistivity overlay.

The empirical equation for calculating TOC in clay-rich rocks from $\Delta \log R$ is as follows.

$$
\mathrm{TOC}=\Delta \log R * 10^{(2.297-0.1688 * \mathrm{LOM})}
$$

where

TOC $=$ Total organic carbon content measured in $\mathrm{wt} \%$.

LOM= Level of maturity.

Due to lack of core data, the $R_{o}$ of Sembar Formation is calculated from burial history using the software Petro-mod and co-relate the values of $R_{o}$ coal rank table to determine he LOM at given value of $R_{o}$. The burial history plots indicate the main features of thick sequence depositional sediments. These plots also show the tectonic subsidence of the well in study normalized from start of burial. With the help of [15] we divided the zones of hydrocarbon in this study well. The TOC of Sembar Formation of study well Bilal North-01 is calculated from Passey's methods with density/resistivity overlay method and its curves shown in (Figure 5). The TOC ranges in the Sembar Formation of this well has the poor to good potential resource. The average range of TOC is about $0.5 \%-2.5 \%$. 


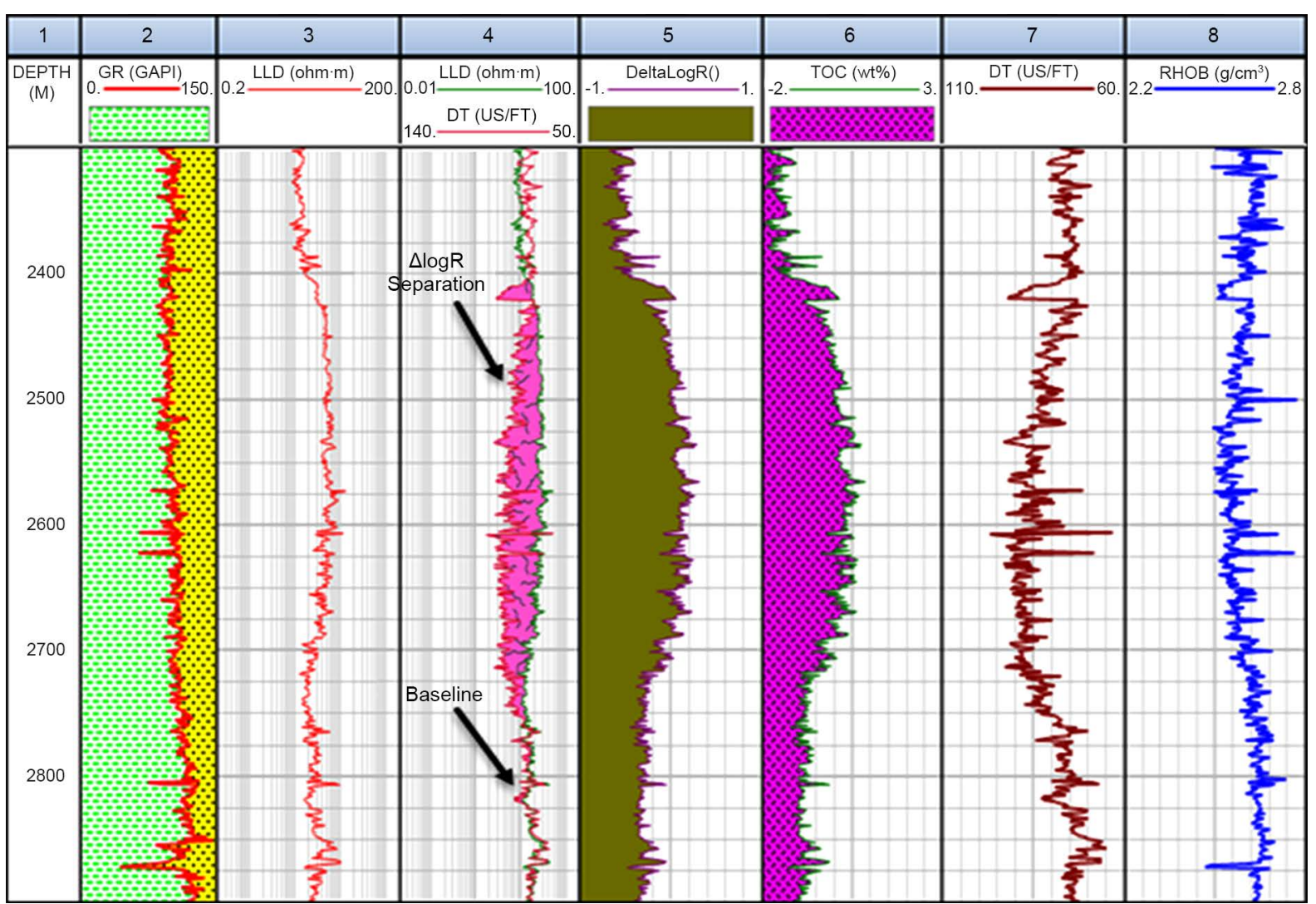

Figure 5. Logging results of Bilal North-01, track description is as follows: Track 1: Depth; Track 2: Gamma Ray; Track 3: Resistivity Log; Track 4: LLD and DT; Track 5: $\Delta \log R$; Track 6: TOC (wt\%); Track 7: Sonic Log; Track 8: Density Log.

This study is to investigate the Sember Formation as a possible source rock. With the help of wire line data of Bilal North-01 it has been estimated that the Sembar rock is a good reservoir potential. The result of TOC shows a good concentration of TOC in the Sember Formation.

\section{Model to Compute Rock Physics Properties of Shale Gas}

Rock Physics describes a reservoir rock in terms of its physical properties such as porosity, rigidity, compressibility etc. and the relationship between these properties [16]. Rock Physics establish relations between these material properties and the observed seismic response, and to develop a predictive theory so that these properties may be detected seismically. Establishing relationship between seismic expression and physical rock properties therefore requires (1) knowledge about the elastic properties of the pore fluid and rock frame, and (2) models for rock-fluid interactions. Modeling the effects of fluid on rock velocity and density is a basic method used to ascertain the influence of pore fluids on seismic data. In this study, to compute the seismic properties the relationships to find out compressional and shear wave velocities for silicates rock is used. This relationship is:

$$
V_{p}=1.16 V_{s}+1.36
$$

where the $V_{p}$ is $p$-wave velocity and $V_{s}$ is shear wave velocity in $\mathrm{km} / \mathrm{sec} . V_{p}$ is calculated from sonic log of study wells. To compute the elastic properties such as shear, bulk modulus, Young's modulus and Poisson's ratio we use the following relationship of $P$ and $S$-wave velocities with density and elastic properties as

$$
\begin{gathered}
\mu=\rho * V_{s}^{2} \\
K=\rho *\left(V_{p}^{2}-\frac{4}{3} V_{s}^{2}\right)
\end{gathered}
$$




$$
\begin{gathered}
E=\frac{9 K \mu}{3 K+\mu} \\
\sigma=0.5\left(V_{p}^{2}-2 * V_{s}^{2}\right) /\left(V_{p}^{2}-V_{s}^{2}\right)
\end{gathered}
$$

where $\mu$ is shear modulus, $\rho$ is density $\mathrm{g} / \mathrm{cm}^{3}, K$ is bulk modulus, $E$ is Young's modulus and $\sigma$ is Poisson's ratio. Kerogen content has a significant impact on the seismic properties of organic-rich shale as kerogen is the main source of TOC. The effect of kerogen content increases the porosity and reduces the density so that a connection between TOC and porosity and density can be established. From the mass-balance equation the relationship between volume of kerogen $\left(V_{k r}\right)$ and TOC is given by [17].

$$
V_{k r}=\left(\mathrm{TOC} / C_{k}\right) *\left(\rho_{b}-\rho_{f} \varnothing / \rho_{k}(1-\varnothing)\right)
$$

where

$C_{k}=0.7-0.85$ depending on maturity level;

$\phi=$ porosity;

$\rho_{b}=$ bulk density;

$\rho_{f}=$ fluid density is $0.8 \mathrm{~g} / \mathrm{cm}^{3}$ for oil shale and $0.5 \mathrm{~g} / \mathrm{cm}^{3}$ for gas shale;

$\rho_{k}=$ kerogen density vary from $1.2-1.4 \mathrm{~g} / \mathrm{cm}^{3}$ depending on maturity.

The volume of kerogen of study wells is calculated from above equation. The cross plot of $V_{k r}$ and TOC and NPHI (porosity) of study wells show the linear relationship.

(Figure 6) shows the 3-D model of effect of porosity and kerogen on TOC.

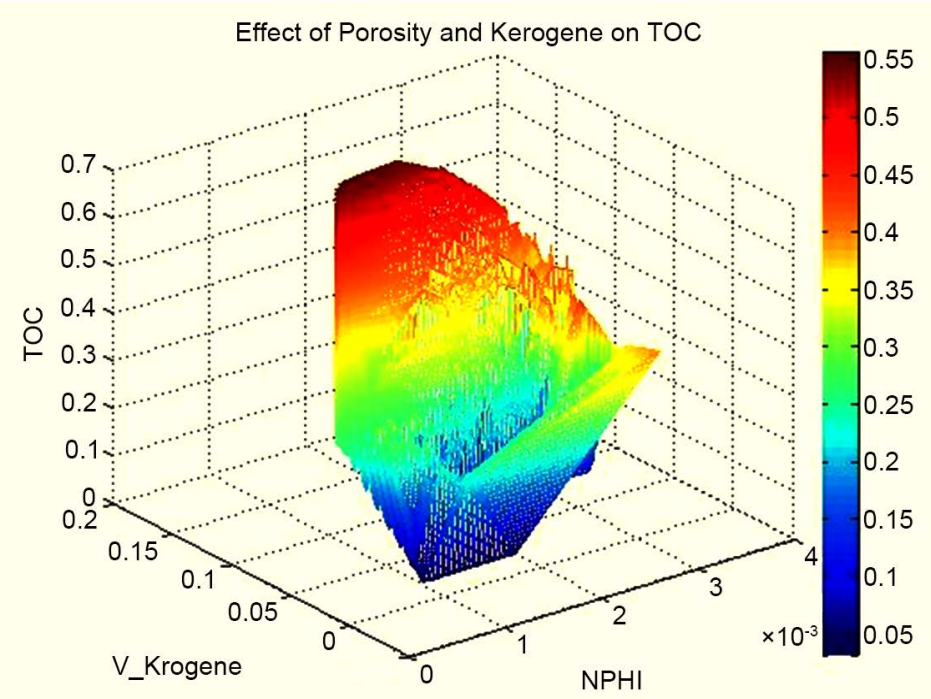

Figure 6. Effect of porosity and kerogen on TOC.

\section{Effect of TOC on Rock Physics Properties}

The petro-physical modeling and rock property analysis play the role of bridge and link. The aim is to seek a relationship between petro-physical properties (such as TOC) and elastic properties such as $\left(V_{p}, V_{s}, P\right.$-impedance, Shear modulus, bulk modulus, Young's modulus and Poisson's modulus ratio) through rock physical analysis technology. From the modeling results we see that bulk density, $P$ - and $S$-wave velocities and $P$-impedance reduce in the organic-rich intervals as compared to non-source intervals. In the study well the $V_{p}$ has the range of $3600-4700 \mathrm{~m} / \mathrm{sec}$ and Vshas range of $1900-2900 \mathrm{~m} / \mathrm{sec}$. For example, TOC may have a positive co-relation with the silica content, and an inverse co-relation with the clay content. In such situation, the decrease in velocities due to high TOC is partially offset by an increase in the stiffer quartz mineral and decrease in $P$-impedance is the result of increase in clay content. 


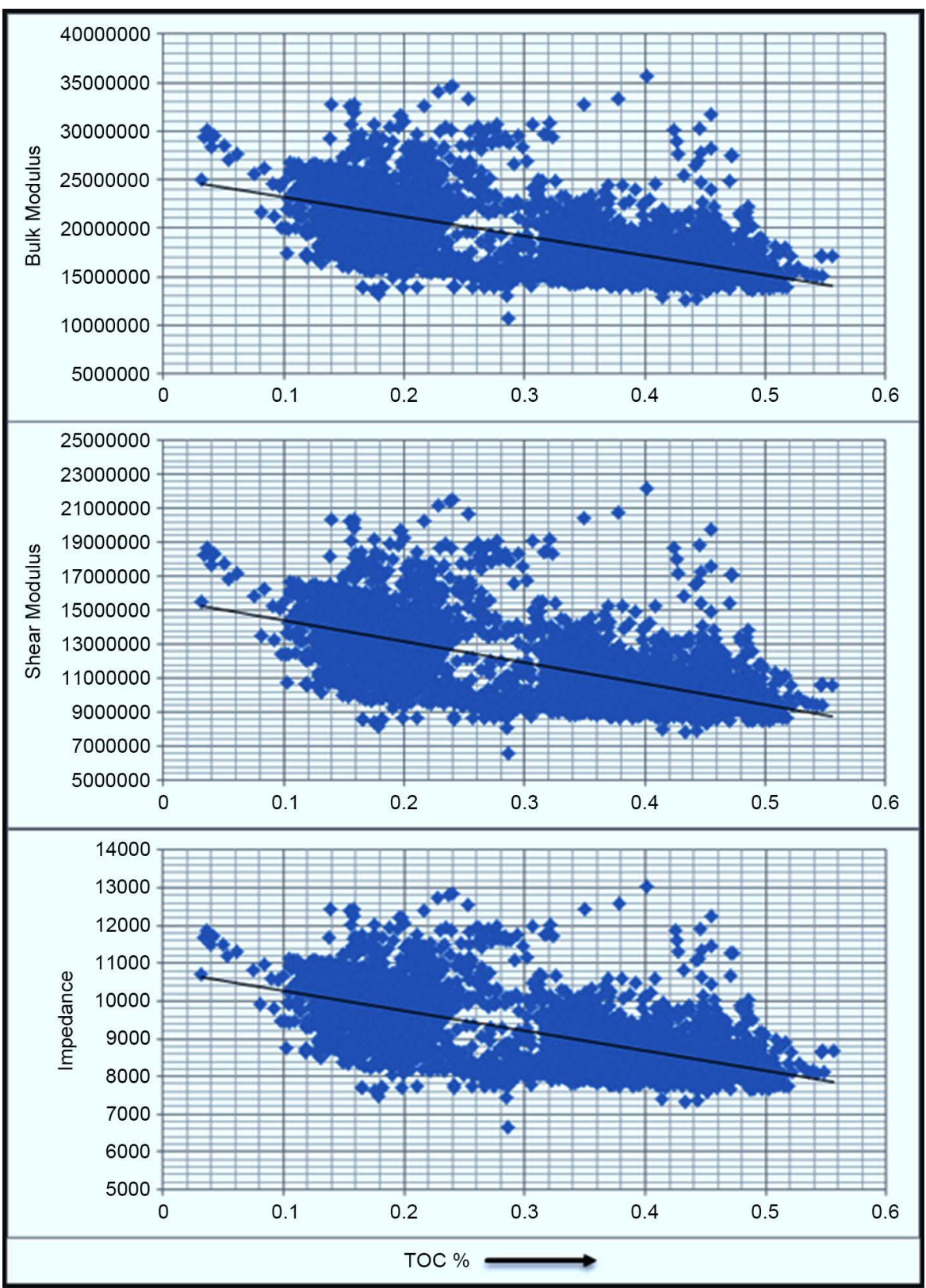

Figure 7. General trend of rock physics properties in Sember Formation bulk modulus VS TOsC $\%$, shear modulus VS TOC\%, impedance VS TOC $\%$.

(Figure 7) above shows the general trend of Rock Physical properties in Sember Formation. Bulk modulus and shear modulus indicate the elastic behavior of the rock. The modeling results of relationship among bulk modulus, shear modulus and TOC show the high TOC content at low value of bulk and shear modulus. Bulk modulus measure of the incompressibility if the rock it is treated as porosity indication. Low value of bulk modulus shows the high porosity and high TOC in the rock. On the other hand shear modulus indicates the lithology. Elastic parameter, such as Young's modulus indicates which rocks are brittle. Through the cross plots of Young's modulus (vertical axis) and Poisson's ratio (horizontal axis), we observe that zones with high Young's modulus (ability to maintain a fracture) and low Poisson's ratio (propensity to resist failure under stress) will be more brittle (higher volume of minerals such as quartz, pyrite and calcite) and have higher reservoir quality (TOC and porosity are both high). On the other hand high Poisson's ratio and low Young's modulus indicate rock is ductile [18]. 


\section{Conclusion}

The Sember Formation has good resource potential for shale gas and has a good concentration of TOC. The log behavior of sonic, resistivity and gamma ray increases and density decreases in organic rich source interval as compared to non-source interval. Modeling results show that TOC has linear relationship with volume of kerogen and porosity and both increase with increase in TOC contents. Elastic properties such as bulk modulus determine the rock incompressibility and have the high value of bulk modulus at organic rich source interval, which is indicator of porosity. Young's and shear modulus determine the brittleness of the rock and both have high value at zone of high TOC.

\section{References}

[1] Powell, C.McA, Roots, S.R. and Veevers, J.J. (1988) Pre-Breakup Continental Extension in East Gondwanaland and the Early Opening of the Eastern Indian Ocean. Tectonophysics, 155, 261-283. http://dx.doi.org/10.1016/0040-1951(88)90269-7

[2] Banks, C.J. and Warburton, J. (1986) Passive-Roof Duplex Geometry in the Frontal Structures of the Kirthar and Suleiman Mountain Belts, Pakistan. Journal of Structural Geology, 8, 229-237. http://dx.doi.org/10.1016/0191-8141(86)90045-3

[3] Passey, Q.R., Bohaces, K.M., Esch, W.L., Klimentidis, R. and Sinha, S. (2010) From Oil-Prone Source Rock to GasProducing Shale Reservoir, Geologic and Petrophysical Characterization of Unconventional Shale Gas Reservoirs. International Oil and Gas Conference and Exhibition in China, 8-10 June 2010, Beijing, 1-29. http://dx.doi.org/10.2118/131350-ms

[4] Quadri, I.B. (1986) Petroleum Geology of Pakistan, PPL, Karachi, Pakistan, 212.

[5] Harilal (2012) Integration of Well Logs for Seismic-Guided Sand Mapping in the Barail Coal-Shale Sequence of Geleki Field. The Leading Edge, 31, 18-22. http://dx.doi.org/10.1190/1.3679322

[6] Chen, S., Zhu, Y., Wang, H., Liu, H., Wei, W. and Fang, J. (2011) Shale Gas Reservoir Characterization: A Typical Case in the Southern Sichuan Basin of China. Energy, 36, 6609-6616. http://dx.doi.org/10.1016/j.energy.2011.09.001

[7] Glorioso, J.C., Ralttia, A. and Repsol (2012) Unconventional Reservoirs: Basic Petrophysical Concepts for Shale Gas. European Unconventional Resources Conference, Vienna, 20-22 March 2012, 1-38. http://dx.doi.org/10.2118/153004-ms

[8] Alexander, T., Baihly, J., Boyer, C., Clark, B., Waters, G., Jochen, V., Calvez, J.L., Lewis, R., Miller, C.K., Thaeler, J. and Toelle, B.E. (2011) Shale Gas Revolution. Oilfield Review Autumn, 23, 40-55.

[9] Hood, A., Gutjahar, C.C.M. and Heacock, R.L. (1975) Organic Metamorphism and the Generation of Petroleum. AAPG Bulletin, 59, 986-996.

[10] Lecompte, B. and Hursan, G. (2010) Quantifying Source Rock Maturity from Logs: How to Get More than TOC from Delta Log R. SPE Annual Technical Conference and Exhibition, 19-22 September 2010, Florence. http://dx.doi.org/10.2118/133128-MS

[11] Schmoker, J.W. (1994) Volumetric Calculation of Hydrocarbons Generated. Memoirs-American Association of Petroleum Geologists, 323.

[12] Langford, F.F. and Blanc-Valleron, M.-M. (1990) Interpreting Rock-Eval Pyrolysis Data Using Graphs of Pyrolizable Hydrocarbons vs. Total Organic Carbon (1). AAPG Bulletin, 74, 799-804.

[13] Creaney, S. and Passey, Q.R. (1993) Recurring Patterns of Total Organic Carbon and Source Rock Quality within a Sequence Stratigraphic Framework. AAPG Bulletin, 77, 386-401.

[14] Shiri (2013) Evaluation of Organic Carbon Content and Source Rock Maturity Using Petrophysical Logs and Geochemical Data: Case Study of Horn Valley Siltstone Source Rock, Amadeus Basin, Central Australia. Journal of Zankoy Sulaimani-Part A (JZS-A), 15, 3.

[15] Behar, F. (1997) Thermal Cracking of Kerogen in Open and Closed Systems: Determination of Kinetic Parameters and Stoichiometric Coefficients for Oil and Gas Generation. Organic Geochemistry, 26, 321-339. http://dx.doi.org/10.1016/S0146-6380(97)00014-4

[16] Mavko, G., Mukerji, T. and Dvorkin, J. (2009) Rock Physics Handbook: Tools for Seismic Analysis in Porous Media. Cambridge University Press, Cambridge. http://dx.doi.org/10.1017/CBO9780511626753

[17] Vernik, L. and Milovac, J. (2011) Rock Physics of Organic Shales. The Leading Edge, 30, 318-323. http://dx.doi.org/10.1190/1.3567263

[18] Holden, T., Pendrel, J., Jenson, F. and Mesdag, P. (2012) Rock Properties for Success in Shales. Jascon CGG, 1-11. 